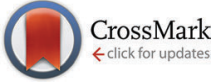

Cite this: Phys. Chem. Chem. Phys., 2015, 17, 3697

Received 10th October 2014, Accepted 2nd December 2014

DOI: $10.1039 / c 4 c p 04592 k$

www.rsc.org/pccp

\section{Electrochemical oxidation stability of anions for modern battery electrolytes: a CBS and DFT study $\dagger$}

\author{
Erlendur Jónsson* and Patrik Johansson
}

\begin{abstract}
The electrochemical stability vs. oxidation is a crucial property of anions in order to be suitable as components in lithium-ion batteries. Here the applicability of a number of computational approaches and methods to assess this property, employing a wide selection of DFT functionals, has been studied using the $\operatorname{CCSD}(T) / C B S$ method as the reference. In all, the vertical anion oxidation potential, $\Delta E_{\mathrm{v}}$, is a fair way to calculate the stability vs. oxidation, however, a functional of at least hybrid quality is recommended. In addition, the chemical hardness, $\eta$, is identified as a novel approach to calculate the stability vs. oxidation.
\end{abstract}

\section{Introduction}

Electrolytes are a key component of batteries and their electrochemical stability windows (ESWs); the potential range wherein none of its components breaks down due to oxidation or reduction, currently limit the capabilities of Li-ion batteries (LIBs). ${ }^{1}$ This is due to the high voltages possible for LIBs, often above $4 \mathrm{~V}$. As there is a strong desire to produce even higher voltage cathodes, ${ }^{2}$ to allow for even higher energy density LIBs - a very high oxidation stability (preferably $>5 \mathrm{~V} v s$. $\mathrm{Li}^{+} / \mathrm{Li}$ ) is aimed at for future electrolytes. For the complementary/competing sodiumion battery technology, ${ }^{3}$ currently seeing a rapid increase in attention, the overall development is foreseen to take the same direction. In order to reduce trial-and-error efforts, tools to predict electrochemical stability from chemical structure alone are of large interest. Generally, one way is by in silico screening, which allows for rapid evaluation of candidates for future synthesis.

Indeed, the ESWs of electrolyte solvents has been tackled computationally previously. ${ }^{4-6}$ This is in part due to the large importance of the solid electrolyte interphase (SEI) passivation layer on the LIB anode, formed by (controlled) electrolyte degradation. ${ }^{7}$ As the solvent tends to be reduced, the reduction limit of the ESW has had focus on the solvent, with extensive studies to understand the SEI formation. ${ }^{8-11}$ While the reduction limit of the anions has been studied in special solvents such as ionic liquids, ${ }^{12-14}$ the anions are not in general reduced in LIB (or SIB) electrolytes. The creation of a SEI,

Department of Applied Physics, Chalmers University of Technology, SE-412 96 Göteborg, Sweden. E-mail: erlendur@chalmers.se; Fax: +46-31-7722090

$\dagger$ Electronic supplementary information (ESI) available: A table showing the extrapolation details of the CBS approach, the $\Delta E_{\mathrm{v}}$ and $\eta$ values for a number of additional anions and functionals. See DOI: $10.1039 / \mathrm{c} 4 \mathrm{cp} 04592 \mathrm{k}$ partially by anion reduction, is a vast subject outside the scope of this paper.

In contrast, it is the (lithium) salt anion that often sets the oxidation limit, e.g. for $\mathrm{ClO}_{4}{ }^{-}$it is $6.1 \mathrm{~V} v$ s. $\mathrm{Li}^{+} / \mathrm{Li}$, while it is $6.8 \mathrm{~V}$ for $\mathrm{PF}_{6}{ }^{-}$in the same solvent. ${ }^{15}$ In contrast, the solvents used are known to have a fair stability vs. oxidation, e.g. the standard blend of ethylene and dimethyl carbonate (EC/DMC) was found to have a limit of $6.7 \mathrm{~V} v s . \mathrm{Li}^{+} / \mathrm{Li}^{4}{ }^{4}$ The stability of the anions versus oxidation are therefore often reported whenever novel salts for LIBs or SIBs are reported, either as experimental ${ }^{16}$ or computed ${ }^{17}$ values.

The experimentally measured ESWs have some variance due to the large number of factors affecting the final value, such as the sweep rate, solvent(s), and electrode(s) used..$^{4,15,18,19}$ Thus reference values for the ESWs, e.g. the intrinsic anion redox potentials, properties solely of the anions and independent of the electrode/ solvent chemistry and physics, are highly warranted.

For the anion oxidation stability, a common approach is to calculate the HOMO energy, ${ }^{20} E_{\mathrm{HOMO}}$, due to the correlation between $E_{\text {Hомо }}$ and the oxidation stability (based on the Koopmans theorem $^{21}$ ). This approach can for example utilize Hartree-Fock (HF) methods with a small to medium sized basis set (e.g. 6-31G* or $\left.6-311+\mathrm{G}^{*}\right)$ and is applicable to a vast number of compounds as it is computationally inexpensive.

To increase the accuracy, electron correlation must be taken in to account, such as with density functional theory (DFT). Unfortunately, the Koopmans theorem is often not valid within the DFT formalism, due to the poor quality of the orbitals, ${ }^{22}$ despite their physical relevance. ${ }^{23-25}$ Thus an alternative approach, using the energy difference from a vertical excitation, is often used, either within the Frank-Condon approximation ${ }^{26,27}\left(\Delta E_{\mathrm{v}}\right)$ or allowing also for geometry relaxation of the excited state ${ }^{28}$ to obtain the ionization potential (IP). Both approaches are illustrated in Fig. 1. 


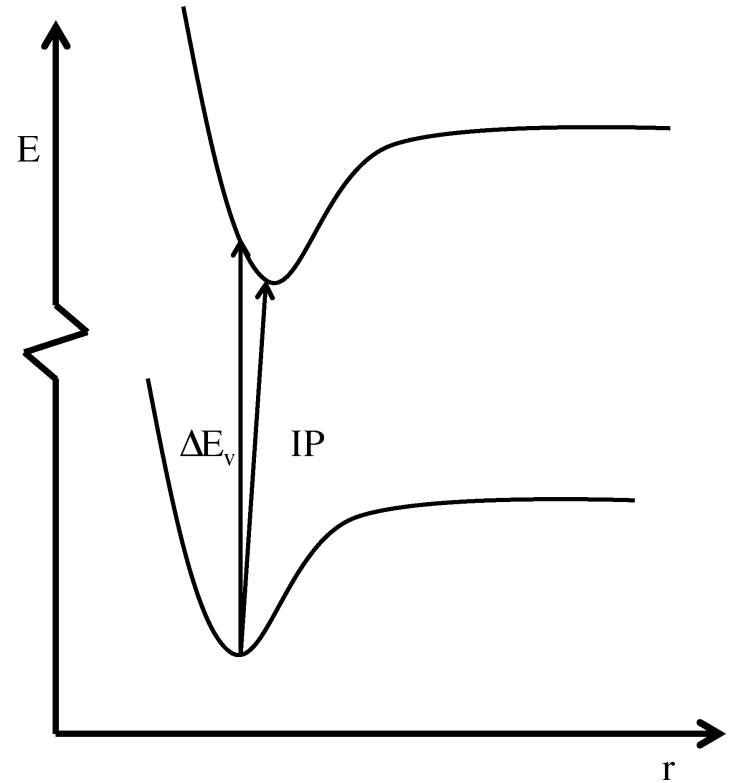

Fig. 1 Illustration of the different approaches used to calculate the anion oxidation potential using DFT; the vertical excitation energy $\left(\Delta E_{\mathrm{v}}\right)$ and the ionization potential (IP).

As hybrid (or better) functionals are recommended for anions, ${ }^{22}$ the computational cost for such calculations is higher than for a pure HF calculation, as this approach at least involves an extra singlepoint calculation and significantly higher if geometry optimization of the excited state is performed. Allowing for geometry relaxation, however, also allows for a thermodynamic approach. ${ }^{28,29}$ If doublehybrid functionals are used, the computational cost increases even more.

Yet another approach is to study the chemical hardness, $\eta$ - a concept that arises naturally from conceptual DFT: ${ }^{30}$

$$
\eta=\frac{1}{2}\left(\frac{\partial^{2} E}{\partial N^{2}}\right)_{v(r)}=\frac{1}{2}\left(\frac{\partial \mu}{\partial N}\right)_{v(r)}
$$

which is the resistance of the electronic chemical potential, $\mu$, to the changing of the number of electrons. To our knowledge, this is only the second attempt to utilize this concept for the anion ESW. ${ }^{31}$

Here the first systematic study involving $\operatorname{CCSD}(\mathrm{T}), \mathrm{MP} 2$, and DFT calculations with a series of basis sets is presented - employed to obtain reference values for the intrinsic anion oxidation potentials at the complete basis set (CBS) limit. This enables a thorough assessment of the applicability and performance of the various methods available to calculate intrinsic oxidation potentials of anions. ${ }^{26-28}$

\section{Computational methodology}

A number of anions that all at some point have been considered for LIB electrolytes were selected to be studied in detail (a subset of those previously studied by $\mathrm{us}^{32}$ ); $\mathrm{BF}_{4}{ }^{-}, \mathrm{PF}_{6}{ }^{-}, \mathrm{ClO}_{4}{ }^{-}$, TFSI $\left(\left[\left(\mathrm{CF}_{3} \mathrm{SO}_{2}\right)_{2} \mathrm{~N}\right]^{-}\right)$, BOB $\left(\left[\mathrm{B}\left(\mathrm{C}_{2} \mathrm{O}_{4}\right)_{2}\right]^{-}\right)$, TDI $\left(\mathrm{C}_{5} \mathrm{~N}_{4} \mathrm{CF}_{3}{ }^{-}\right)$, Tf $\left(\mathrm{CF}_{3} \mathrm{SO}_{3}{ }^{-}\right.$), $\mathrm{N}_{5}{ }^{-}, \mathrm{N}_{5} \mathrm{C}_{2}{ }^{-}, \mathrm{N}_{5} \mathrm{C}_{4}{ }^{-}$(two isomers), $\mathrm{N}_{5} \mathrm{C}_{6}{ }^{-}$(two isomers),
$\operatorname{Im}\left(\mathrm{BF}_{3}\right)_{2}{ }^{-}$and $\mathrm{N}_{5} \mathrm{C}_{10}{ }^{-}$. A number of small anions were also added, as a control set. Additionally, some anions were found to be too large for the CBS method, and only partial results are therefore listed in the ESI. $\dagger$

Single point energies were calculated with each of the following DFT functionals (with the $6-311+\mathrm{G}^{*}$ basis set): B3LYP, ${ }^{33-35}$ BMK, $^{36}$ PBE0, ${ }^{37}$ TPSS, ${ }^{38}$ TPSSh, $^{39}$ the M06 suite (M06, M06-2X, M06-L), ${ }^{40}$ VSXC, ${ }^{41,42}$ B2PLYP, ${ }^{43}$ and mPW2PLYP. ${ }^{44}$ The B3LYP/6-311+G* equilibrium geometry was used for the anions and for the oxidized and reduced species.

The $\operatorname{CCSD}(\mathrm{T})$ calculations with the aug-cc-pVXZ $(\mathrm{X}=\mathrm{T}, \mathrm{Q}, 5)$ basis sets used an extrapolation to the CBS limit: ${ }^{45}$

$$
E(n)=E^{\mathrm{CBS}}+A n^{-3}
$$

where $n$ is the cardinality of the basis set used, i.e. $n=3$ for augcc-pVTZ. This formula, chosen for its simplicity and performance, ${ }^{46}$ was used to extrapolate the HF, MP2 and $\operatorname{CCSD}(\mathrm{T})$ energies. A separate extrapolation for the correlated part of the energy and the HF energy proved to have no significant effect on the results.

Due to the $\mathrm{O}\left(\mathrm{N}^{7}\right)$ scaling of $\operatorname{CCSD}(\mathrm{T})$, the rise in computational cost and time is staggering $\$$ - making the full CCSD(T)/CBS treatment not feasible at present for all of the anions. Therefore, a mixed CBS method was employed, wherein a correction term is added to a MP2/CBS value (also extrapolated using eqn (2)). The correction term, $\Delta \operatorname{CCSD}(\mathrm{T})$, was calculated with $\mathrm{MP} 2 / 6-31 \mathrm{G}^{*}$ and $\operatorname{CCSD}(\mathrm{T}) /$ $6-31 G^{*}$ (a small but reasonable basis set for our purpose ${ }^{47}$ ):

$$
\Delta \mathrm{CCSD}(\mathrm{T})=E_{\mathrm{CCSD}(\mathrm{T})}^{6-31 \mathrm{G}^{*}}-E_{\mathrm{MP} 2}^{6-31 \mathrm{G}^{*}}
$$

The $\operatorname{CCSD}(\mathrm{T}) / \mathrm{CBS}$ values are then:

$$
E_{\mathrm{CCSD}(\mathrm{T})}^{\mathrm{CBS}}=E_{\mathrm{MP} 2}^{\mathrm{CBS}}+\Delta \mathrm{CCSD}(\mathrm{T})
$$

Values obtained with this method are forthcoming designated as $\triangle \mathrm{CBS}$.

A finite difference scheme was used for the calculation of the chemical hardness:

$$
\eta=\frac{1}{2}\left(\frac{\partial^{2} E}{\partial N^{2}}\right)_{v(r)}=\frac{1}{2} \times\left(E_{N+1}-2 E_{N}+E_{N-1}\right)
$$

where $E_{N}$ is the energy of the anion, and $E_{N+1}$ and $E_{N-1}$ are the energies of the reduced and oxidized anion species, respectively. The reduced anion species, $E_{N+1}$, could be considered an unphysical approximation, however, this is countered by the experimental observation of such species. ${ }^{12}$

$E_{\mathrm{HOMO}}$ values were extracted from the $\mathrm{HF} / 6-311+\mathrm{G}^{*}$ calculations. The vertical anion oxidation potentials, $\Delta E_{\mathrm{v}}$, were calculated using single point energies $\left(\Delta E_{\mathrm{v}}=E_{N-1}-E_{N}\right)$. As the experimental results in general are given $v s$. $\mathrm{Li}^{+} / \mathrm{Li}$, the computed $\Delta E_{\mathrm{v}}$ are all shifted by $1.46 \mathrm{~V}^{8}$ The Gaussian $09^{48}$ program was used for all calculations and the Int = ExactBasisTransform keyword was used for the CBS calculations in order to ensure that no basis functions that contribute to the energy were pruned away during basis transformations.

† Illustrating this, moving from $\mathrm{TZ}$ (230 basis functions) to $5 \mathrm{Z}$ (635 basis functions) for $\mathrm{BF}_{4}{ }^{-}$, increases the CPU time needed by a factor 100 . 


\section{Results \& discussion}

The analysis of the results starts with a comparison between the CBS and the $\triangle \mathrm{CBS}$ methods for small anions, followed by a further analysis of $\triangle \mathrm{CBS}$ values of larger anions. Thereafter, we compare the performance of different functionals. Each section treats and discusses the HOMO, $\Delta E_{\mathrm{v}}$, and $\eta$ approaches.

\subsection{CBS vs. $\Delta \mathrm{CBS}$}

Only a portion of the anions were small enough to allow $\operatorname{CCSD}(\mathrm{T})$ calculations with the aug-cc-pV5Z basis sets. Therefore, most anions had to resort to the $\triangle$ CBS measure rather than CBS. As MP2 energies are included in the results of the $\operatorname{CCSD}(\mathrm{T})$ calculations, the anions in Table 1 can also function as an internal benchmark for the $\triangle$ CBS method. In general, the values obtained from the $\triangle$ CBS method are close to the values from the $\operatorname{CCSD}(\mathrm{T}) /$ CBS method. This holds for both the $\Delta E_{\mathrm{v}}$ and $\eta$ approaches, showing the general validity of the $\triangle \mathrm{CBS}$ method. For $\mathrm{BF}_{4}{ }^{-}$, however, the $\triangle \mathrm{CBS}$ values are $10 \%$ and $6 \%$ lower than the CBS values, giving a possible upper bound for possible errors. The $\mathrm{BF}_{4}{ }_{4}^{-}$ values are close to revised experimental value of $6.2 \mathrm{Vvs.} \mathrm{Li}^{+} / \mathrm{Li}$.

Surprisingly, neither the CBS nor the $\Delta$ CBS $\Delta E_{\mathrm{v}}$ values for the halides are in the expected order of $\mathrm{F}^{-}>\mathrm{Cl}^{-}>\mathrm{Br}^{-}$, instead $\mathrm{Cl}^{-}>\mathrm{Br}^{-}>\mathrm{F}^{-}$is observed. Comparing the $E_{\text {ox }}$ values with the $\Delta E_{\mathrm{v}}$ values for the halides, shows that the $\Delta E_{\mathrm{v}}$ value is drastically lower. Similarly, the experimental $E_{\text {ox }}$ value of $\mathrm{ClO}_{4}{ }^{-}$ of $6.0 \mathrm{Vvs.} \mathrm{Li}^{+} / \mathrm{Li}$ is far higher than expected from the CBS

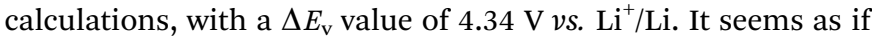
the atomic anions have a problem with a proper radical description affecting this measure.

The hardness, $\eta$, has the expected ordering for the halides, furthermore, the hardness values are on average closer to the $E_{\mathrm{ox}}$ than the $\Delta E_{\mathrm{v}}$ values. For example, $\mathrm{BF}_{4}{ }^{-}$has a hardness that is well within the range of the $E_{\mathrm{ox}}$ values, despite having the highest difference between $\eta$ values calculated by CBS and $\Delta$ CBS. $\mathrm{BF}_{4}{ }^{-}$is also the only anion with a higher $\Delta E_{\mathrm{v}}$ than $\eta$. $\mathrm{ClO}_{4}{ }^{-}$is the only anion for which all $E_{\mathrm{ox}}$ values are larger than the hardness.

Table 1 Anions with full CCSD(T)/CBS results. All values are given in $\mathrm{V} v$. $\mathrm{Li}^{+} / \mathrm{Li}$, except $\eta$ and $E_{\text {Hомо }}(\mathrm{eV})$. $E_{\mathrm{ox}}$ is experimental values

\begin{tabular}{|c|c|c|c|c|c|c|}
\hline \multirow[b]{2}{*}{ Anion } & \multirow{2}{*}{$\begin{array}{l}\frac{\Delta E_{\mathrm{v}}}{\operatorname{CCSD}(\mathrm{T}) /} \\
\operatorname{CBS}\end{array}$} & \multirow{2}{*}{$\begin{array}{l}\frac{\Delta E_{\mathrm{v}}}{\Delta \mathrm{CBS}} \\
-\end{array}$} & \multirow{2}{*}{$\frac{\eta}{\operatorname{CCSD}(\mathrm{T}) /}$} & \multirow{2}{*}{$\frac{\eta}{\Delta \mathrm{CBS}}$} & \multirow{2}{*}{$\begin{array}{l}\frac{E_{\text {номо }}}{\mathrm{HF} / 6-} \\
311+\mathrm{G}^{*}\end{array}$} & \multirow{2}{*}{$\begin{array}{l}E_{\mathrm{ox}} \\
\text { Experimental }\end{array}$} \\
\hline & & & & & & \\
\hline$\overline{\mathrm{Br}^{-}}$ & 2.12 & 2.10 & 4.37 & 4.36 & -3.79 & $4.1^{49}$ \\
\hline $\mathrm{F}^{-}$ & 1.96 & 1.99 & 6.02 & 6.07 & -4.08 & $5.9^{49}$ \\
\hline $\mathrm{Cl}^{-}$ & 2.21 & 2.25 & 4.89 & 4.89 & -4.83 & $4.4^{49}$ \\
\hline $\mathrm{HS}^{-}$ & 0.89 & 0.93 & 2.93 & 2.92 & -2.56 & - \\
\hline $\mathrm{HF}_{2}^{-}$ & 4.93 & 4.97 & 5.40 & 5.44 & -7.73 & - \\
\hline $\mathrm{NO}_{3}^{-}$ & 2.72 & 2.74 & 4.40 & 4.30 & -6.33 & - \\
\hline $\mathrm{OCN}^{-}$ & 2.33 & 2.35 & 4.06 & 4.07 & -4.35 & - \\
\hline $\mathrm{SCN}^{-}$ & 2.16 & 2.22 & 3.64 & 3.66 & -3.84 & - \\
\hline $\mathrm{BF}_{4}^{-}$ & 7.03 & 6.35 & 6.42 & 6.06 & -10.45 & $\begin{array}{l}6.2 ;^{28} 6.6, \\
8.3^{15}\end{array}$ \\
\hline $\mathrm{BrO}_{3}^{-}$ & 3.44 & 3.54 & 4.48 & 4.55 & -6.04 & - \\
\hline $\mathrm{ClO}_{4}^{-}$ & 4.34 & 4.36 & 5.06 & 5.06 & -7.89 & $\begin{array}{l}6.0 ;^{28} 6.1, \\
7.0^{15}\end{array}$ \\
\hline $\mathrm{HCO}_{2}^{-}$ & 2.80 & 2.85 & 3.80 & 3.81 & -5.11 & - \\
\hline $\mathrm{BH}_{4}^{-}$ & 3.21 & 3.23 & 3.90 & 3.85 & -5.19 & - \\
\hline
\end{tabular}

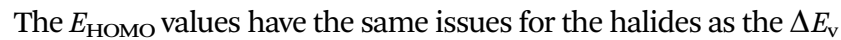
values, i.e. wrong ordering. Unfortunately, it is not the same ordering, i.e. $\mathrm{Cl}^{-}>\mathrm{F}^{-}>\mathrm{Br}^{-}$. Looking at the $E_{\mathrm{ox}}$ values, the $E_{\mathrm{HOMO}}$ value for $\mathrm{BF}_{4}{ }^{-}$is very large, $-10.45 \mathrm{eV}$, far larger than expected. It is not clear what causes $\mathrm{BF}_{4}{ }^{-}$to stand out for all measures.

\section{$3.2 \Delta \mathrm{CBS}$}

In Table 2 we show the $\triangle$ CBS values only for the larger anions for which CBS was not viable. A comparison vs. experimental data show that the $\Delta E_{\mathrm{v}}$ approach tends to overestimate the oxidation potentials. This includes the ВОВ (by $1.63 \mathrm{~V}$ ) and MOB (by $1.09 \mathrm{~V}$ ) anions - with BOB correctly described to be more stable. Furthermore, some values are very close to the measured $E_{\text {ox }}$ with $\operatorname{Im}\left(\mathrm{BF}_{3}\right)_{2}{ }^{-}$as the stellar example (only $0.07 \mathrm{~V}$ difference). For some other anions, a definite comparison is not possible, due to the large variations in $E_{\text {ox }}$ values. These include TFSI, where the $\Delta E_{\mathrm{v}}$ value is close to some of the $E_{\mathrm{ox}}$ values. Both $\mathrm{AsF}_{6}{ }^{-}$and $\mathrm{PF}_{6}{ }^{-}$have $\Delta E_{\mathrm{v}}$ values close to the $E_{\mathrm{ox}}$ maximum values.

Overall, the hardness has qualitatively similar predictive power, as the $\Delta E_{\mathrm{v}}$ values. In general, the $\eta$ values are close to the $E_{\mathrm{ox}}$ values. Starting with the anions with single $E_{\mathrm{ox}}$ values, the $\eta$ values are slightly higher, however, the difference is not as large as for the $\Delta E_{\mathrm{v}}$ values. ВOB and MOB have the largest differences, both $0.8 \mathrm{~V}$, between $E_{\text {ox }}$ and $\eta$. The $\eta$ values of TFSI, Tf, $\mathrm{PF}_{6}{ }^{-}$and $\mathrm{AsF}_{6}{ }^{-}$are all within the range of reported $E_{\mathrm{ox}}$ values. Looking at the relative stability of BOB and MOB, we note that the difference between the $\Delta E_{\mathrm{v}}$ values $(0.6 \mathrm{~V})$ is far higher than the $\eta$ values $(0.1 \mathrm{eV})$, the latter being closer to the $E_{\text {ox }}$ difference.

The $E_{\mathrm{HOMO}}$ values show an unexpected ordering of oxidative stability; the third most stable anion, is the BOB anion $(-8.81 \mathrm{eV})$, more stable than TFSI $(-8.60 \mathrm{eV})$ and TDI $(-5.54 \mathrm{eV})$, despite both having higher $E_{\text {ox }}$ values than BOB. It is also notable that

Table 2 Anions with $\Delta$ CBS results for $\Delta E_{\mathrm{v}}$ and $\eta$. All values are given in $\mathrm{V}$ vs. $\mathrm{Li}^{+} / \mathrm{Li}$, except $\eta$ and $E_{\text {Hомо }}$ which are in eV

\begin{tabular}{|c|c|c|c|c|}
\hline & & & & $\underline{E_{\mathrm{Ox}}}$ \\
\hline Anion & $\Delta E_{\mathrm{v}}$ & $\eta$ & $E_{\text {НОмо }}$ & Experimental \\
\hline $\mathrm{N}_{5}^{-}$ & 4.54 & 5.80 & -6.10 & - \\
\hline $\mathrm{NCN}_{2}{ }^{-}$ & 2.86 & 4.44 & -4.82 & - \\
\hline $\mathrm{AsF}_{6}{ }^{-}$ & 8.38 & 7.02 & -12.13 & $6.5 ;^{28} 6.8,8.6^{15}$ \\
\hline $\mathrm{PF}_{6}^{-}$ & 8.57 & 7.21 & -11.67 & $6.3 ;^{28} 6.8,8.4^{15}$ \\
\hline $\mathrm{C}(\mathrm{CN})_{3}{ }^{-}$ & 2.78 & 3.81 & -4.60 & - \\
\hline $\mathrm{CH}_{3} \mathrm{COO}^{-}$ & 1.48 & 2.99 & -5.10 & - \\
\hline $\mathrm{N}_{5} \mathrm{C}_{2}^{-}$ & 4.27 & 4.62 & -5.70 & - \\
\hline $\mathrm{Tf}$ & 5.31 & 5.04 & -7.50 & $5.0,5.9 ;^{28} 6.0,7.0^{15}$ \\
\hline FSI & 5.34 & 5.24 & -8.66 & $>4.5^{50}$ \\
\hline $\mathrm{N}_{5} \mathrm{C}_{4} \mathrm{a}^{-}$ & 4.32 & 5.51 & -5.78 & $>4.0^{51,52}$ \\
\hline $\mathrm{N}_{5} \mathrm{C}_{4} \mathrm{~b}^{-}$ & 4.05 & 5.01 & -5.55 & - \\
\hline $\mathrm{N}_{5} \mathrm{C}_{6} \mathrm{a}^{-}$ & 4.45 & 5.02 & -6.04 & - \\
\hline $\mathrm{N}_{5} \mathrm{C}_{6} \mathrm{~b}^{-}$ & 4.08 & 5.37 & -5.49 & - \\
\hline BOB & 6.13 & 5.30 & -8.81 & $4.5^{53}$ \\
\hline $\mathrm{N}_{5} \mathrm{C}_{8}^{-}$ & 4.20 & 4.47 & -5.80 & - \\
\hline TDI & 4.02 & 5.21 & -5.54 & $4.80^{54}$ \\
\hline TFSI & 6.12 & 5.62 & -8.60 & $5.3,6.1 ;^{28} 6.3,7.1 ;^{15} 5.40^{55}$ \\
\hline $\operatorname{Im}\left(\mathrm{BF}_{3}\right)_{2}^{-}$ & 4.92 & 4.53 & -6.32 & $4.85^{16}$ \\
\hline MOB & 5.49 & 5.23 & -8.72 & $4.4^{56}$ \\
\hline $\mathrm{N}_{5} \mathrm{C}_{10}^{-}$ & 4.59 & - & -6.24 & - \\
\hline $\mathrm{B}\left(\mathrm{CH}_{3}\right)_{4}^{-}$ & 3.01 & 3.57 & -5.34 & $2.9^{15}$ \\
\hline
\end{tabular}


$E_{\text {Homo }}$ is the only measure that indicates $\mathrm{AsF}_{6}{ }^{-}$to be more stable than $\mathrm{PF}_{6}{ }^{-}$, as obtained by the maximum $E_{\mathrm{Ox}}$ values.

\subsection{Functional dependency}

The analysis of the DFT functional performance is discussed first for $\Delta E_{\mathrm{v}}$ and subsequently for $\eta$ and grouped by functional type.

The $\Delta E_{\mathrm{v}}$ values from DFT and HF in Table 3 in general underestimate $\Delta E_{\mathrm{v}}$ - using $\Delta \mathrm{CBS}$ as reference - with an average deviation negative for $\mathrm{HF}$ and all functionals (except M06-2X, $+0.01 \mathrm{~V}$ ), as seen in Fig. 2 .

Starting with $\mathrm{HF}$, one notable issue is the values for $\mathrm{F}^{-}$and $\mathrm{HS}^{-}$, both negative ( $\left.v s . \mathrm{Li}^{+} / \mathrm{Li}\right)$. In practice this means that $\mathrm{HF}$ predicts that these anions would reduce $\mathrm{Li}^{+}$. $\mathrm{HF}$ also has the highest average and standard deviations. Notably, the Hückel anions $\left(\mathrm{N}_{5} \mathrm{C}_{2 n}{ }^{-}\right.$, excluding $\left.\mathrm{N}_{5}{ }^{-}\right)$have far lower values than the $\triangle \mathrm{CBS}$ reference, with the difference ranging from $1.47 \mathrm{~V}$ to $2.09 \mathrm{~V}$. The highly symmetric and quite special anion $\mathrm{N}_{5}{ }^{-}$is, however, slightly higher in energy than the reference, by $0.18 \mathrm{~V}$. Other notable anions are $\mathrm{AsF}_{6}{ }^{-}$and $\mathrm{PF}_{6}{ }^{-}$, higher by $0.78 \mathrm{~V}$ and $0.38 \mathrm{~V}$, respectively.

Each of the functionals used have different issues, a few observations, grouped by functional complexity, are here highlighted.

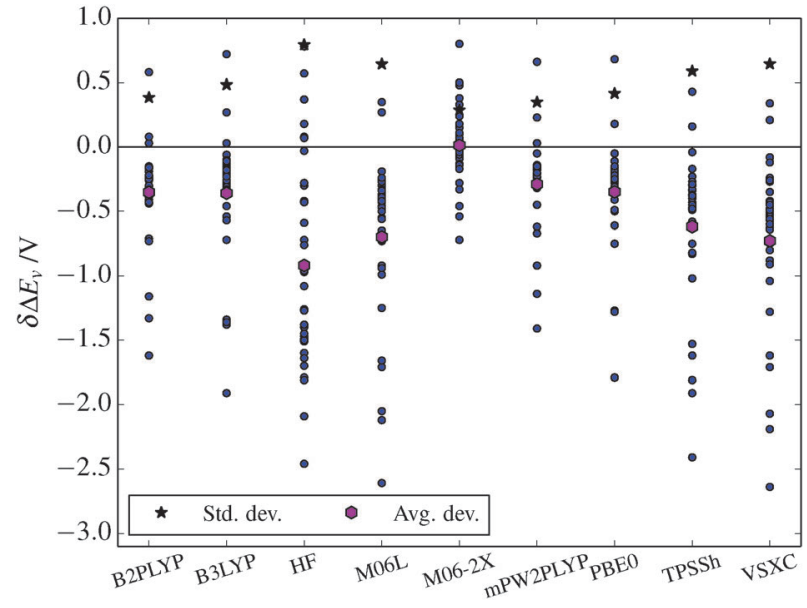

Fig. 2 The deviation, $\delta \Delta E_{v}$ of the $\Delta E_{\mathrm{v}}$ value from the $\Delta C B S$ reference value for each of the methods. Average and standard deviations are also shown.

Starting with the non-hybrid functionals, VSXC has the largest average deviation $(-0.73 \mathrm{~V})$ of the DFT functionals. It underestimates the $\Delta E_{\mathrm{V}}$ of a few anions by more than $2 \mathrm{~V}: \mathrm{PF}_{6}{ }^{-}$is underestimated by $2.65 \mathrm{~V}, \mathrm{AsF}_{6}{ }^{-}$by $2.19 \mathrm{~V}$, and BOB by $2.07 \mathrm{~V}$.

Table 3 Vertical oxidation potential $\left(\Delta E_{\mathrm{v}}\right)$ of anions from selected DFT functionals and HF. $\Delta \mathrm{CBS}$ values given for comparison. All values in $\mathrm{V} v$ s. $\mathrm{Li}^{+} / \mathrm{Li}$. The average and standard deviations are comparative to the $\triangle \mathrm{CBS}$ values

\begin{tabular}{|c|c|c|c|c|c|c|c|c|c|c|}
\hline Anion & $\Delta \mathrm{CBS}$ & B2PLYP & B3LYP & $\mathrm{HF}$ & M06-L & M06-2X & mPW2PLYP & PBE0 & TPSSh & VSXC \\
\hline $\mathrm{Br}^{-}$ & 2.10 & 1.91 & 2.13 & 1.02 & 1.85 & 2.03 & 1.93 & 2.05 & 2.06 & 2.02 \\
\hline $\mathrm{Cl}^{-}$ & 1.99 & 2.02 & 2.26 & 1.02 & 2.26 & 2.23 & 2.02 & 2.17 & 2.15 & 2.20 \\
\hline $\mathrm{F}^{-}$ & 2.25 & 1.84 & 2.03 & -0.21 & 1.70 & 1.71 & 1.80 & 1.76 & 1.78 & 2.01 \\
\hline $\mathrm{HS}^{-}$ & 0.93 & 0.62 & 0.87 & -0.33 & 0.74 & 0.84 & 0.63 & 0.77 & 0.76 & 0.81 \\
\hline $\mathrm{HF}_{2}^{-}$ & 4.97 & 4.72 & 4.60 & 4.94 & 4.05 & 5.12 & 4.81 & 4.56 & 4.22 & 4.09 \\
\hline $\mathrm{NO}_{3}^{-}$ & 2.74 & 2.30 & 2.64 & 3.31 & 2.19 & 3.22 & 2.45 & 2.63 & 2.31 & 2.11 \\
\hline $\mathrm{OCN}^{-}$ & 2.35 & 2.20 & 2.23 & 0.95 & 2.05 & 2.37 & 2.21 & 2.16 & 2.05 & 2.00 \\
\hline $\mathrm{SCN}^{-}$ & 2.22 & 1.96 & 2.08 & 0.95 & 1.95 & 2.19 & 1.98 & 2.05 & 1.99 & 1.95 \\
\hline $\mathrm{BF}_{4}^{-}$ & 6.35 & 6.43 & 5.98 & 6.05 & 5.36 & 6.85 & 6.58 & 6.03 & 5.52 & 5.31 \\
\hline $\mathrm{BrO}_{3}{ }^{-}$ & 3.54 & 3.19 & 3.31 & 2.95 & 2.89 & 3.61 & 3.27 & 3.28 & 3.05 & 2.97 \\
\hline $\mathrm{ClO}_{4}^{-}$ & 4.36 & 4.20 & 4.20 & 4.08 & 3.80 & 4.74 & 4.31 & 4.21 & 3.88 & 3.72 \\
\hline $\mathrm{HCO}_{2}{ }^{-}$ & 2.85 & 2.14 & 2.31 & 2.13 & 1.91 & 2.57 & 2.23 & 2.24 & 2.03 & 1.94 \\
\hline $\mathrm{BH}_{4}^{-}$ & 3.23 & 3.00 & 3.11 & 2.27 & 2.80 & 3.10 & 3.02 & 3.01 & 2.96 & 2.70 \\
\hline $\mathrm{N}_{5}^{-}$ & 4.54 & 4.15 & 4.26 & 4.72 & 3.81 & 4.72 & 4.25 & 4.26 & 3.95 & 3.74 \\
\hline $\mathrm{N}(\mathrm{CN})_{2}^{-}$ & 2.86 & 2.67 & 2.65 & 1.37 & 2.49 & 2.88 & 2.68 & 2.62 & 2.47 & 2.38 \\
\hline $\mathrm{AsF}_{6}{ }^{-}$ & 8.38 & 7.22 & 7.00 & 9.16 & 6.26 & 8.24 & 7.46 & 7.11 & 6.47 & 6.19 \\
\hline $\mathrm{PF}_{6}^{-}$ & 8.57 & 6.95 & 6.66 & 8.94 & 5.96 & 7.85 & 7.16 & 6.78 & 6.16 & 5.93 \\
\hline $\mathrm{C}(\mathrm{CN})_{3}{ }^{-}$ & 2.78 & 2.53 & 2.60 & 1.27 & 2.45 & 2.80 & 2.55 & 2.58 & 2.44 & 2.34 \\
\hline $\mathrm{CH}_{3} \mathrm{COO}^{-}$ & 1.48 & 2.06 & 2.20 & 0.72 & 1.83 & 2.28 & 2.14 & 2.16 & 1.91 & 1.82 \\
\hline $\mathrm{N}_{5} \mathrm{C}_{2}^{-}$ & 4.27 & 4.10 & 4.08 & 2.48 & 3.94 & 4.28 & 4.11 & 4.06 & 3.93 & 3.85 \\
\hline Tf & 5.31 & 4.90 & 3.97 & 5.39 & 3.60 & 5.41 & 5.02 & 4.96 & 3.69 & 3.60 \\
\hline FSI & 5.34 & 5.10 & 5.08 & 4.92 & 4.65 & 5.67 & 5.20 & 5.11 & 4.76 & 4.59 \\
\hline $\mathrm{N}_{5} \mathrm{C}_{4} \mathrm{a}^{-}$ & 4.32 & 4.10 & 4.02 & 2.23 & 3.86 & 4.26 & 4.11 & 4.01 & 3.87 & 3.78 \\
\hline $\mathrm{N}_{5} \mathrm{C}_{4} \mathrm{~b}^{-}$ & 4.05 & 3.86 & 3.87 & 2.58 & 3.71 & 4.10 & 3.88 & 3.86 & 3.72 & 3.62 \\
\hline $\mathrm{N}_{5} \mathrm{C}_{6} \mathrm{a}^{-}$ & 4.45 & 4.19 & 4.19 & 2.85 & 4.04 & 4.44 & 4.21 & 4.19 & 4.05 & 3.94 \\
\hline $\mathrm{N}_{5} \mathrm{C}_{6} \mathrm{~b}^{-}$ & 4.08 & 3.78 & 3.77 & 2.27 & 3.61 & 4.02 & 3.80 & 3.77 & 3.63 & 3.52 \\
\hline BOB & 6.13 & 4.80 & 4.77 & 5.70 & 4.08 & 5.67 & 4.99 & 4.85 & 4.32 & 4.06 \\
\hline $\mathrm{N}_{5} \mathrm{C}_{8}{ }^{-}$ & 4.20 & 3.95 & 3.97 & 2.70 & 3.81 & 4.23 & 3.97 & 3.98 & 3.83 & 3.71 \\
\hline TDI & 4.02 & 3.80 & 3.79 & 2.32 & 3.60 & 4.05 & 3.82 & 3.77 & 3.64 & 3.57 \\
\hline TFSI & 6.12 & 5.39 & 5.40 & 4.74 & 4.46 & 5.79 & 5.45 & 5.37 & 4.59 & 4.50 \\
\hline $\operatorname{Im}\left(\mathrm{BF}_{3}\right)_{2}^{-}$ & 4.92 & 4.76 & 4.81 & 3.47 & 4.68 & 4.99 & 4.77 & 4.77 & 4.63 & 4.66 \\
\hline MOB & 5.49 & 5.06 & 4.92 & 5.56 & 4.24 & 5.60 & 5.18 & 4.99 & 4.47 & 4.21 \\
\hline $\mathrm{N}_{5} \mathrm{C}_{10}{ }^{-}$ & 4.59 & 4.26 & 4.26 & 2.95 & 4.09 & 4.55 & 4.28 & 4.28 & 4.11 & 3.99 \\
\hline $\mathrm{B}\left(\mathrm{CH}_{3}\right)_{4}{ }^{-}$ & 3.01 & 2.65 & 2.55 & 2.08 & 2.36 & 2.84 & 2.69 & 2.52 & 2.39 & 2.21 \\
\hline Avg. dev. & & -0.35 & -0.36 & -0.92 & -0.70 & 0.01 & -0.29 & -0.35 & -0.62 & -0.73 \\
\hline Std. dev. & & 0.39 & 0.49 & 0.81 & 0.65 & 0.29 & 0.36 & 0.42 & 0.60 & 0.65 \\
\hline
\end{tabular}


A few other anions are underestimated by more than $1 \mathrm{~V}$ : Tf, TFSI, MOB and $\mathrm{BF}_{4}{ }^{-}$. Two anions have their $\Delta E_{\mathrm{v}}$ overestimated compared to the reference; $\mathrm{Cl}^{-}$(by $0.22 \mathrm{~V}$ ) and $\mathrm{CH}_{3} \mathrm{COO}^{-}$ (by $0.33 \mathrm{~V}$ ). M06-L has the second highest average deviation $(-0.70 \mathrm{~V})$ of the DFT functionals. The problematic anions are the same as for VSXC with only slightly different values.

The hybrid functionals have better performance characteristics, however, B3LYP has the same problematic cases as VSXC and M06-L. Though, as the average deviation implies, the errors are smaller in magnitude; $\mathrm{PF}_{6}{ }^{-}$is underestimated by $1.91 \mathrm{~V}$ and $\mathrm{AsF}_{6}{ }^{-}$by $1.38 \mathrm{~V}$ and most others anions are below $1 \mathrm{~V}$ in difference. However, the overestimates of $\mathrm{CH}_{3} \mathrm{COO}^{-}$and $\mathrm{Cl}^{-}$ are somewhat large, $0.72 \mathrm{~V}$ and $0.28 \mathrm{~V}$, respectively. PBE0 has similar performance characteristics as B3LYP - including the same problems with $\mathrm{PF}_{6}{ }^{-}$, underestimated by $1.79 \mathrm{~V}, \mathrm{BOB}$ by $1.28 \mathrm{~V}$, and $\mathrm{AsF}_{6}{ }^{-}$by $1.27 \mathrm{~V}$.

TPSSh performs somewhat worse than B3LYP. It is also the only hybrid functional that has any value that is underestimated by more than $2 \mathrm{~V}: \mathrm{PF}_{6}{ }^{-}$by $2.41 \mathrm{~V}$. The deviations for AsF6 and BOB are also large: $1.91 \mathrm{~V}$ and $1.81 \mathrm{~V}$, respectively.

M06-2X has the distinction of having the lowest deviation of all of the functionals. However, it has a number of overestimates such as $\mathrm{CH}_{3} \mathrm{COO}^{-}$by $0.80 \mathrm{~V}, \mathrm{BF} 4$ by $0.50 \mathrm{~V}$, and $\mathrm{NO}_{3}{ }^{-}$by $0.48 \mathrm{~V}$. Furthermore, the underestimates are low; $\mathrm{PF}_{6}{ }^{-} 0.72 \mathrm{~V}, \mathrm{~F}^{-} 0.53 \mathrm{~V}$, and $\mathrm{BOB} 0.46 \mathrm{~V}$. It is also notable that $\mathrm{AsF}_{6}{ }^{-}$is underestimated by only $0.14 \mathrm{~V}$. Interestingly, the $\mathrm{BF}_{4}{ }^{-}$value of $6.85 \mathrm{~V}$ is closer to the CBS value $(7.03 \mathrm{~V})$, than the $\triangle \mathrm{CBS}$ value $(6.35 \mathrm{~V})$.

The two double hybrid functionals have very small deviations, as MPW2PLYP has the second lowest average deviation $(-0.29 \mathrm{~V})$ and only has two values that differ by more than $1 \mathrm{~V}$ : $\mathrm{PF}_{6}{ }^{-}$and $\mathrm{BOB}$ are underestimated by $1.41 \mathrm{~V}$ and $1.14 \mathrm{~V}$, respectively. B2PLYP is similar to MPW2PLYP, however, it has a slightly higher deviation; $-0.35 \mathrm{~V}$. It also has three anions that differ by more than $1 \mathrm{~V}$ from the reference: $\mathrm{PF}_{6}{ }^{-}$ is underestimated by $1.62 \mathrm{~V}, \mathrm{AsF}_{6}{ }^{-}$by $1.16 \mathrm{~V}$, and $\mathrm{BOB}$ by $1.33 \mathrm{~V}$.

When the results from all the DFT functionals are taken together, a few points become apparent. First, a larger number of electronegative groups present in the anion structure, tends to cause worse results. Thus heavily fluorinated molecules in general have $\Delta E_{\mathrm{v}}$ values underestimated by 1-2 $\mathrm{V}$. This is readily apparent for the $\mathrm{PF}_{6}{ }^{-}$and $\mathrm{AsF}_{6}{ }^{-}$anions. This is also an issue for $\mathrm{BOB}$, but to a less extent for the MOB variant, which has the less electronegative malonato moiety. This could be an issue for

Table 4 Hardness $(\eta)$ of anions from selected DFT functionals and HF. $\Delta$ CBS values given for comparison. All values in eV. The average and standard deviations are comparative to $\triangle$ CBS values

\begin{tabular}{|c|c|c|c|c|c|c|c|c|c|c|}
\hline Anion & $\triangle \mathrm{CBS}$ & B2PLYP & B3LYP & $\mathrm{HF}$ & M06-L & M06-2X & mPW2PLYP & PBE0 & TPSSh & VSXC \\
\hline $\mathrm{Br}^{-}$ & 4.36 & 4.92 & 4.93 & 4.69 & 4.86 & 4.88 & 4.94 & 4.90 & 4.94 & 5.06 \\
\hline $\mathrm{Cl}^{-}$ & 4.89 & 5.75 & 5.75 & 5.50 & 5.83 & 5.74 & 5.76 & 5.71 & 5.73 & 5.43 \\
\hline $\mathrm{F}^{-}$ & 6.07 & 8.47 & 8.42 & 7.83 & 8.33 & 8.30 & 8.46 & 8.30 & 8.31 & 8.58 \\
\hline $\mathrm{HS}^{-}$ & 2.92 & 4.17 & 4.16 & 3.87 & 4.14 & 4.12 & 4.18 & 4.10 & 4.10 & 4.14 \\
\hline $\mathrm{HF}_{2}^{-}$ & 5.44 & 8.13 & 7.89 & 8.69 & 7.85 & 8.25 & 8.19 & 7.94 & 7.78 & 7.78 \\
\hline $\mathrm{NO}_{3}^{-}$ & 4.30 & 5.47 & 5.50 & 5.88 & 5.58 & 5.80 & 5.51 & 5.55 & 5.34 & 5.37 \\
\hline $\mathrm{OCN}^{-}$ & 4.07 & 4.73 & 4.66 & 4.26 & 4.80 & 4.73 & 4.73 & 4.63 & 4.59 & 4.44 \\
\hline $\mathrm{SCN}^{-}$ & 3.66 & 4.23 & 4.20 & 3.91 & 4.33 & 4.27 & 4.24 & 4.19 & 4.18 & 4.02 \\
\hline $\mathrm{BF}_{4}^{-}$ & 6.06 & 6.76 & 6.43 & 6.74 & 6.29 & 6.94 & 6.82 & 6.48 & 6.25 & 6.00 \\
\hline $\mathrm{BrO}_{3}{ }^{-}$ & 4.55 & 4.87 & 4.86 & 4.83 & 4.85 & 5.08 & 4.91 & 4.84 & 4.76 & 4.65 \\
\hline $\mathrm{ClO}_{4}^{-}$ & 5.06 & 5.81 & 5.72 & 6.07 & 5.97 & 6.08 & 5.86 & 5.78 & 5.65 & 5.43 \\
\hline $\mathrm{HCO}_{2}^{-}$ & 3.81 & 5.10 & 4.77 & 4.86 & 4.74 & 4.95 & 5.14 & 4.73 & 4.64 & 4.52 \\
\hline $\mathrm{BH}_{4}^{-}$ & 3.85 & 5.10 & 5.07 & 4.88 & 5.04 & 4.96 & 5.11 & 5.01 & 5.01 & 4.75 \\
\hline $\mathrm{N}_{5}^{-}$ & 5.80 & 6.61 & 6.49 & 7.09 & 6.48 & 6.86 & 6.64 & 6.57 & 6.39 & 6.39 \\
\hline $\mathrm{N}(\mathrm{CN})_{2}^{-}$ & 4.44 & 4.51 & 4.43 & 4.05 & 4.65 & 4.56 & 4.52 & 4.43 & 4.39 & 4.11 \\
\hline $\mathrm{AsF}_{6}^{-}$ & 7.02 & 6.54 & 6.29 & 7.86 & 6.27 & 7.16 & 6.64 & 6.42 & 6.11 & 5.83 \\
\hline $\mathrm{PF}_{6}^{-}$ & 7.21 & 6.91 & 6.65 & 8.15 & 6.32 & 7.36 & 7.00 & 6.75 & 6.32 & 6.10 \\
\hline $\mathrm{C}(\mathrm{CN})_{3}{ }^{-}$ & 3.81 & 4.19 & 4.16 & 3.75 & 4.39 & 4.28 & 4.20 & 4.17 & 4.12 & 3.81 \\
\hline $\mathrm{CH}_{3} \mathrm{COO}^{-}$ & 2.99 & 4.29 & 4.28 & 3.71 & 4.31 & 4.35 & 4.33 & 4.26 & 4.16 & 4.04 \\
\hline $\mathrm{N}_{5} \mathrm{C}_{2}^{-}$ & 4.62 & 5.07 & 4.99 & 5.00 & 5.45 & 5.14 & 5.08 & 4.98 & 4.94 & 4.75 \\
\hline $\mathrm{Tf}$ & 5.04 & 5.67 & 5.11 & 6.05 & 5.19 & 5.97 & 5.72 & 5.62 & 5.01 & 4.85 \\
\hline FSI & 5.24 & 5.56 & 5.44 & 5.80 & 5.61 & 5.89 & 5.60 & 5.52 & 5.35 & 5.12 \\
\hline $\mathrm{N}_{5} \mathrm{C}_{4} \mathrm{a}^{-}$ & 5.51 & 5.02 & 4.78 & 4.33 & 4.79 & 4.99 & 5.00 & 4.80 & 4.75 & 4.74 \\
\hline $\mathrm{N}_{5} \mathrm{C}_{4} \mathrm{~b}^{-}$ & 5.01 & 5.06 & 4.85 & 4.74 & 4.86 & 5.09 & 5.05 & 4.88 & 4.82 & 4.37 \\
\hline $\mathrm{N}_{5} \mathrm{C}_{6} \mathrm{a}^{-}$ & 5.02 & 4.68 & 4.48 & 4.31 & 4.47 & 4.69 & 4.68 & 4.50 & 4.45 & 4.43 \\
\hline $\mathrm{N}_{5} \mathrm{C}_{6} \mathrm{~b}^{-}$ & 5.37 & 4.65 & 4.44 & 4.14 & 4.44 & 4.65 & 4.64 & 4.46 & 4.41 & 4.39 \\
\hline BOB & 5.30 & 5.05 & 4.87 & 5.76 & 4.69 & 5.37 & 5.12 & 4.94 & 4.69 & 4.48 \\
\hline $\mathrm{N}_{5} \mathrm{C}_{8}{ }^{-}$ & 4.47 & 4.32 & 4.11 & 3.95 & 4.09 & 4.33 & 4.31 & 4.13 & 4.08 & 4.05 \\
\hline TDI & 5.21 & 4.74 & 4.54 & 4.26 & 4.54 & 4.74 & 4.73 & 4.55 & 4.51 & 4.49 \\
\hline TFSI & 5.62 & 5.53 & 5.38 & 5.51 & 5.15 & 5.78 & 5.55 & 5.41 & 5.01 & 4.83 \\
\hline $\operatorname{Im}\left(\mathrm{BF}_{3}\right)_{2}^{-}$ & 4.53 & 5.06 & 4.99 & 4.57 & 5.39 & 5.17 & 5.05 & 4.98 & 4.94 & 5.02 \\
\hline МOB & 5.23 & 5.23 & 4.98 & 5.75 & 4.78 & 5.39 & 5.27 & 5.06 & 4.81 & 4.58 \\
\hline $\mathrm{N}_{5} \mathrm{C}_{10}{ }^{-}$ & $-^{a}$ & 4.30 & 4.08 & 3.87 & 4.05 & 4.30 & 4.29 & 4.10 & 4.04 & 4.01 \\
\hline $\mathrm{B}\left(\mathrm{CH}_{3}\right)_{4}{ }^{-}$ & 3.57 & 4.21 & 4.07 & 4.15 & 4.32 & 4.27 & 4.23 & 4.08 & 4.04 & 3.77 \\
\hline Avg. dev. & & 0.49 & 0.35 & 0.45 & 0.39 & 0.61 & 0.52 & 0.38 & 0.26 & 0.13 \\
\hline Std. dev. & & 0.78 & 0.82 & 0.89 & 0.86 & 0.74 & 0.78 & 0.79 & 0.83 & 0.90 \\
\hline
\end{tabular}

${ }^{a} \mathrm{~N}_{5} \mathrm{C}_{10}{ }^{-}$has no reference value and is thus neglected in the statistics. 
future $a b$ initio work on novel electrolyte anions, as they tend to be themed around strongly electronegative groups.

Second, while DFT on the whole results in too low $\Delta E_{\mathrm{v}}$ values, the $\Delta E_{\mathrm{v}}$ value for $\mathrm{CH}_{3} \mathrm{COO}^{-}$is in general overestimated from $0.5 \mathrm{~V}$ to $0.8 \mathrm{~V}$. The $\Delta E_{\mathrm{v}}$ for $\mathrm{Cl}^{-}$is also often overestimated.

Third, in general the performance of the DFT functionals follows the Jacob's ladder of DFT. ${ }^{57}$ The hybrid functionals perform better than the local functionals, VSXC and M06-L, while the double-hybrid functionals, MPW2PLYP and B2PLYP, perform even better. There is one functional that performs far better, M06-2X, though that may be a fortunate cancellation of errors, as this functional is heavily parameterized.

Moving on to the chemical hardness measure, on average the DFT functionals overestimate the hardness (Table 4 and Fig. 3), as all average deviations are positive. Furthermore, with the large standard deviations, there will be outliers for each functional. Each functional must be inspected, following the same analysis layout as above. Starting with VSXC and M06-L, these have the same outliers, albeit differing slightly in magnitude. Both overestimate the $\mathrm{F}^{-}$and $\mathrm{HF}_{2}^{-}$by over $2 \mathrm{eV}$, and also have issues with $\mathrm{CH}_{3} \mathrm{COO}^{-}$and $\mathrm{Cl}^{-}$. The functionals in general underestimate the hardness of the Hückel anions $\left(\mathrm{N}_{5} \mathrm{C}_{2 n}, n=2 \ldots\right)$, and $\mathrm{BOB}$, by $0.5 \mathrm{eV}$ or more. Furthermore, both functionals underestimate $\mathrm{PF}_{6}{ }^{-}$and $\mathrm{AsF}_{6}{ }^{-}$, M06-L by $0.89 \mathrm{eV}$ and $0.75 \mathrm{eV}$ and VSXC by $1.11 \mathrm{eV}$ and $1.20 \mathrm{eV}$, respectively. Interestingly, the average deviations for the two functionals are small, $0.13 \mathrm{eV}$ for VSXC and $0.39 \mathrm{eV}$ for M06-L.

Looking at the hybrid functionals; B3LYP, M06-2X, PBE0, and TPSSh, all reveal the same pattern as for the VSXC and M06-L functionals, e.g. an overestimated hardness for $\mathrm{F}^{-}$and $\mathrm{HF}_{2}{ }^{-}$, in each case by $\geq 2 \mathrm{eV}$. However, the underestimates of the $\mathrm{PF}_{6}{ }^{-}$ and $\mathrm{AsF}_{6}{ }^{-}$anions are much reduced for all the hybrid functionals (except TPSSh). M06-2X has even a slight overestimate of the $\mathrm{PF}_{6}{ }^{-}$and $\mathrm{AsF}_{6}{ }^{-}$, by $0.16 \mathrm{eV}$ and $0.14 \mathrm{eV}$, respectively.

The double hybrid functionals, B2PLYP and mPW2PLYP, have some of the largest average deviations of all the functional of Table 4, however, they have some of the smallest standard deviations, implying that they tend to overestimate the hardness.

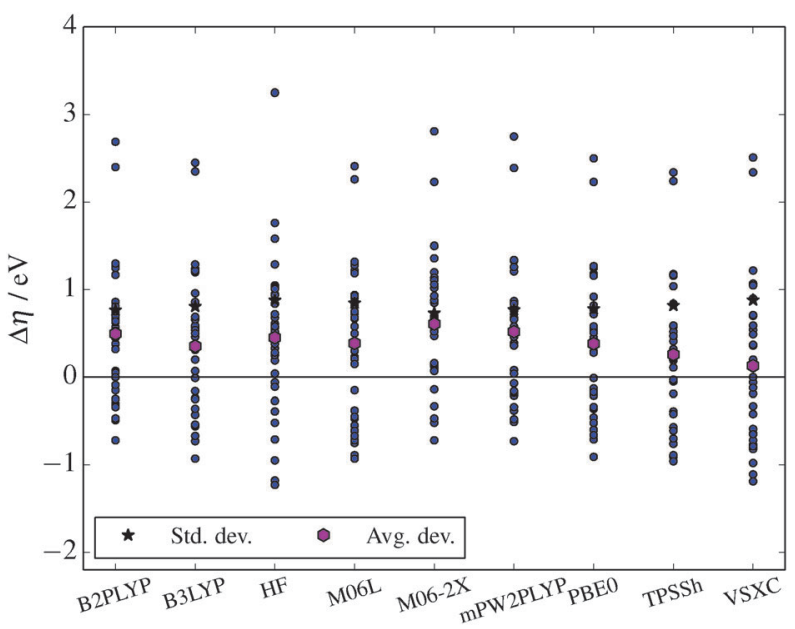

Fig. 3 The deviation of the hardness from the $\triangle$ CBS reference value for each of the methods. Average and standard deviations are also shown.
They also have many of the same outliers as the other functionals, in particular $\mathrm{F}^{-}$and $\mathrm{HF}_{2}^{-}$, which are overestimated by $\geq 2.4 \mathrm{eV}$. Furthermore, $\mathrm{Cl}^{-}$and $\mathrm{CH}_{3} \mathrm{COO}^{-}$continue to have some overestimation ( $\approx 0.8 \mathrm{eV}$ and $1.3 \mathrm{eV}$, respectively). The Hückel anions $\left(\mathrm{N}_{5} \mathrm{C}_{2 n}, n=2 \ldots\right)$, continue to have some underestimation. However, the magnitude of the underestimate for $\mathrm{PF}_{6}{ }^{-}$and $\mathrm{AsF}_{6}{ }^{-}$is smaller than for most of the hybrid functionals, with $0.30 \mathrm{eV}$ and $0.38 \mathrm{eV}$ for B2PLYP and $0.21 \mathrm{eV}$ and $0.38 \mathrm{eV}$ for mPW2PLYP, respectively.

Comparing the deviations from the reference values for both approaches, $\Delta E_{\mathrm{v}}$ (Fig. 2) and $\eta$ (Fig. 3), it must be noted that the magnitude of the deviations of $\eta$ are far larger (note the figure scales). Furthermore, looking at Fig. 1 and 2 of the ESI, $\dagger$ show that while DFT can tackle $\Delta E_{\mathrm{v}}$ calculations, the same is not clear for $\eta$, due to the low correlation with the $\Delta$ CBS values.

\section{Conclusions}

For the calculation of the stability $v s$. oxidation for the present set of anions, using the methodology of $\Delta E_{\mathrm{v}}$, a hybrid (or better yet, double hybrid) functional is recommended. Their resulting $\Delta E_{\mathrm{v}}$ values are closer to the benchmark, surpassing the previously recommended VSXC functional of older works. ${ }^{26,27}$ Out of the DFT functionals tested, M06-2X performs the best.

Using the $E_{\text {Hомо }}$ measure to predict the stability $v s$. oxidation is debatable, due to the unexpected ordering of the anions' oxidative stability. Furthermore, neither the $E_{\mathrm{HOMO}}$ nor the $\Delta E_{\mathrm{v}}$ approaches were able to predict the expected ordering of $\mathrm{F}^{-}>\mathrm{Cl}^{-}>\mathrm{Br}^{-}$.

Hardness is another interesting property to study in connection with oxidation potentials, though the origin of its strong correlation with $E_{\mathrm{ox}}$ is not clear. Out of the many DFT functionals tested, no strong general recommendation can be made, however, the double hybrids and M06-2X are candidates for the calculation of hardnesses.

\section{Acknowledgements}

We would like to thank the Swedish Energy Agency for funding via a VR/STEM grant and SNIC for the computational resources. Prof. Johan Scheers is thanked for his helpful comments and questions. Support to Patrik Johansson from Chalmers Areas of Advance Transport is gratefully acknowledged.

\section{References}

1 K. Xu, Chem. Rev., 2014, 114, 11503-11618.

2 J. B. Goodenough and K.-S. Park, J. Am. Chem. Soc., 2013, 135, 1167-1176.

3 A. Ponrouch, R. Dedryvère, D. Monti, A. E. Demet, J. M. Ateba Mba, L. Croguennec, C. Masquelier, P. Johansson and M. R. Palacn, Energy Environ. Sci., 2013, 6, 2361-2369.

4 K. Xu, S. P. Ding and T. R. Jow, J. Electrochem. Soc., 1999, 146, 4172-4178.

5 X. Zhang, J. K. Pugh and P. N. Ross, J. Electrochem. Soc., 2001, 148, E183-E188. 
6 L. Xing and O. Borodin, Phys. Chem. Chem. Phys., 2012, 14, 12838-12843.

7 R. Fong, U. von Sacken and J. R. Dahn, J. Electrochem. Soc., 1990, 137, 2009-2013.

8 J. M. Vollmer, L. A. Curtiss, D. R. Vissers and K. Amine, J. Electrochem. Soc., 2004, 151, A178-A183.

9 G. V. Zhuang, K. Xu, H. Yang, T. R. Jow and P. N. Ross, J. Phys. Chem. B, 2005, 109, 17567-17573.

10 I. A. Shkrob, Y. Zhu, T. W. Marin and D. Abraham, J. Phys. Chem. C, 2013, 19255-19269.

11 I. A. Shkrob, Y. Zhu, T. W. Marin and D. Abraham, J. Phys. Chem. C, 2013, 19270-19279.

12 P. C. Howlett, E. I. Izgorodina, M. Forsyth and D. R. MacFarlane, Z. Phys. Chem., 2006, 220, 1483-1498.

13 E. Markevich, R. Sharabi, V. Borgel, H. Gottlieb, G. Salitra, D. Aurbach, G. Semrau and M. A. Schmidt, Electrochim. Acta, 2010, 55, 2687-2696.

14 S. P. Ong, O. Andreussi, Y. Wu, N. Marzari and G. Ceder, Chem. Mater., 2011, 23, 2979-2986.

15 M. Ue, M. Takeda, M. Takehara and S. Mori, J. Electrochem. Soc., 1997, 133, 2684-2688.

16 T. J. Barbarich and P. F. Driscoll, Electrochem. Solid-State Lett., 2003, 6, A113-A116.

17 E. Jónsson, M. Armand and P. Johansson, Phys. Chem. Chem. Phys., 2012, 14, 6021-6025.

18 J. M. Tarascon and D. Guyomard, Solid State Ionics, 1994, 69, 293-305.

19 K. Xu and C. A. Angell, J. Electrochem. Soc., 1998, 145, L70-L72.

20 F. Kita, A. Kawakami, J. Nie, T. Sonoda and H. Kobayashi, J. Power Sources, 1997, 68, 307-310.

21 T. Koopmans, Physica, 1934, 1, 104-113.

22 F. Jensen, J. Chem. Theory Comput., 2010, 6, 2726-2735.

23 E. J. Baerends and O. V. Gritsenko, J. Phys. Chem. A, 1997, 101, 5383-5403.

24 R. Stowasser and R. Hoffmann, J. Am. Chem. Soc., 1999, 121, 3414-3420.

25 E. Baerends, Theor. Chem. Acc., 2000, 103, 265-269.

26 P. Johansson, J. Phys. Chem. A, 2006, 110, 12077-12080.

27 P. Johansson, J. Phys. Chem. A, 2007, 111, 1378-1379.

28 M. Ue, A. Murakami and S. Nakamura, J. Electrochem. Soc., 2002, 149, A1572-A1577.

29 O. Borodin, W. Behl and T. R. Jow, J. Phys. Chem. C, 2013, 117, 8661-8682.

30 P. Geerlings, F. De Proft and W. Langenaeker, Chem. Rev., 2003, 103, 1793-1874.

31 P. Johansson, J. Tegenfeldt and J. Lindgren, J. Phys. Chem. A, 2000, 104, 954-961.

32 E. Jónsson and P. Johansson, Phys. Chem. Chem. Phys., 2012, 14, 10774-10779.

33 S. H. Vosko, L. Wilk and M. Nusair, Can. J. Phys., 1980, 58, 1200-1211.

34 C. Lee, W. Yang and R. G. Parr, Phys. Rev. B: Condens. Matter Mater. Phys., 1988, 37, 785-789.

35 A. D. Becke, J. Chem. Phys., 1993, 98, 5648-5652.

36 A. D. Boese and J. M. L. Martin, J. Chem. Phys., 2004, 121, 3405-3416.
37 C. Adamo and V. Barone, J. Chem. Phys., 1999, 110, 6158-6170.

38 J. Tao, J. Perdew, V. Staroverov and G. Scuseria, Phys. Rev. Lett., 2003, 91, 146401.

39 J. Perdew, A. Ruzsinszky, J. Tao, G. Csonka and G. Scuseria, Phys. Rev. A: At., Mol., Opt. Phys., 2007, 76, 042506.

40 Y. Zhao and D. G. Truhlar, Theor. Chim. Acta, 2008, 120, 215-241.

41 T. Van Voorhis and G. E. Scuseria, J. Chem. Phys., 1998, 109, 400-410.

42 T. Van Voorhis and G. E. Scuseria, J. Chem. Phys., 2008, 129, 219901.

43 S. Grimme, J. Chem. Phys., 2006, 124, 034108.

44 T. Schwabe and S. Grimme, Phys. Chem. Chem. Phys., 2006, 8, 4398.

45 T. Helgaker, W. Klopper, H. Koch and J. Noga, J. Chem. Phys., 1997, 106, 9639-9646.

46 D. Feller, K. A. Peterson and J. Grant Hill, J. Chem. Phys., 2011, 135, 044102.

47 M. Pitoňák, T. Janowski, P. Neogrády, P. Pulay and P. Hobza, J. Chem. Theory Comput., 2009, 5, 1761-1766.

48 M. J. Frisch, G. W. Trucks, H. B. Schlegel, G. E. Scuseria, M. A. Robb, J. R. Cheeseman, G. Scalmani, V. Barone, B. Mennucci, G. A. Petersson, H. Nakatsuji, M. Caricato, X. Li, H. P. Hratchian, A. F. Izmaylov, J. Bloino, G. Zheng, J. L. Sonnenberg, M. Hada, M. Ehara, K. Toyota, R. Fukuda, J. Hasegawa, M. Ishida, T. Nakajima, Y. Honda, O. Kitao, H. Nakai, T. Vreven, J. J. A. Montgomery, J. E. Peralta, F. Ogliaro, M. Bearpark, J. J. Heyd, E. Brothers, K. N. Kudin, V. N. Staroverov, R. Kobayashi, J. Normand, K. Raghavachari, A. Rendell, J. C. Burant, S. S. Iyengar, J. Tomasi, M. Cossi, N. Rega, J. M. Millam, M. Klene, J. E. Knox, J. B. Cross, V. Bakken, C. Adamo, J. Jaramillo, R. Gomperts, R. E. Stratmann, O. Yazyev, A. J. Austin, R. Cammi, C. Pomelli, J. W. Ochterski, R. L. Martin, K. Morokuma, V. G. Zakrzewski, G. A. Voth, P. Salvador, J. J. Dannenberg, S. Dapprich, A. D. Daniels, Ö. Farkas, J. B. Foresman, J. V. Ortiz, J. Cioslowski and D. J. Fox, Gaussian 09 Revision B.01.

49 This is calculated from the standard reduction potentials by assuming that the difference between the value for the anion and lithium is the oxidation potential.

50 H.-B. Han, S.-S. Zhou, D.-J. Zhang, S.-W. Feng, L.-F. Li, K. Liu, W.-F. Feng, J. Nie, H. Li, X.-J. Huang, M. Armand and Z.-B. Zhou, J. Power Sources, 2011, 196, 3623-3632.

51 M. Egashira, B. Scrosati, M. Armand, S. Béranger and C. Michot, Electrochem. Solid-State Lett., 2003, 6, A71-A73.

52 M. Armand, private communication.

53 W. Xu and C. A. Angell, Electrochem. Solid-State Lett., 2001, 4, E1-E4.

54 L. Niedzicki, S. Grugeon, S. Laruelle, P. Judeinstein, M. Bukowska, J. Prejzner, P. Szczeciński, W. Wieczorek and M. Armand, J. Power Sources, 2011, 196, 8696-8700.

55 V. R. Koch, L. A. Dominey, C. Nanjundiah and M. J. Ondrechen, J. Electrochem. Soc., 1996, 143, 798-803.

56 W. Xu, A. J. Shusterman, R. Marzke and C. A. Angell, J. Electrochem. Soc., 2004, 151, A632-A638.

57 J. P. Perdew and K. Schmidt, AIP Conf. Proc., 2001, 577, 1-20. 